\title{
Stem Cell Transplantation: Genetic Counselors as a Critical Part of the Process
}

\author{
Heather Zierhut $\cdot$ Kami Wolfe Schneider
}

Published online: 3 April 2014

(c) Springer Science + Business Media New York 2014

\begin{abstract}
Genetic counselors bring unique and important expertise to health care teams that serve patients with genetic conditions treated by hematopoietic stem cell transplantation (HSCT). Genetic counselors are master'strained allied health care professionals who work in collaboration with physicians to guide patients through the complexities of heritable conditions and emerging technologies, including through the diagnostic, HSCT treatment, and post-HSCT processes. This article will review the history of HSCT for genetic conditions, the role of the genetic counselor throughout the HSCT process, and the evolving and expanding role of genetic counselors in current and future stem cell therapies.
\end{abstract}

Keywords Genetic counseling - Bone marrow transplantation · Hematopoietic stem cell · Genetic

\section{Introduction and Background}

Genetic counselors are master's-trained allied health care professionals who work in collaboration with physicians to guide patients through the complexities of heritable conditions. They bring unique and important expertise to

\footnotetext{
H. Zierhut $(\bowtie)$

Department of Genetics, Cell Biology, and Development, University of Minnesota, 420 Delaware St SE, MMC 485, Minneapolis, MN 55401, USA

e-mail: zier0034@umn.edu

K. W. Schneider

Hematology, Oncology, and Bone Marrow Transplant, University of Colorado Denver, Anschutz Medical Campus, 13123 East 16th Avenue, Box 115, Aurora, CO 80045, USA e-mail: kami.wolfe@gmail.com
}

health care teams that serve patients with genetic conditions treated by hematopoietic stem cell transplantation (HSCT) [1]. This article will review the history of HSCT for genetic conditions, the role of the genetic counselor throughout the HSCT process, and the evolving and expanding role of genetic counselors in current and future stem cell therapies.

\section{The History of HSCT for Genetic Conditions}

HSCT is a life-saving and life-threatening treatment for a variety of genetic conditions. HSCT for genetic conditions involves the transplantation of blood-making stem cells typically derived from bone marrow, peripheral blood stem cells, or umbilical cord blood of an unaffected donor to an affected host. Administration of chemotherapy and/or total body irradiation is used to ablate a host's bone marrow. The HSCT recipient is then given stem cells from a donor as well as immunosuppression to permit the engraftment of new healthy hematopoietic stem cells derived from the donor. Treatment by HSCT was attempted and ineffective until the discovery of major histocompatibility antigen (HLA) testing in 1967, which allowed for selection of better matches between donor and recipient HLAs [2, 3]. The first successful HSCT occurred in 1968 in a patient with $\mathrm{X}$-linked severe combined immunodeficiency (SCID) [4]. When clinicians became able to better assess the immunological compatibility of donors and recipients, the devastating consequences of severe graft-versus-host disease were minimized and the uses of HSCT to treat both malignancies and other conditions expanded [5]. Successful HSCTs for other genetic conditions began to surface in 1980 when the first HSCT for an inborn error of metabolism was performed in a patient with mucopolysaccharidosis 
type 1 (Hurler syndrome) [6]. In the same year, a report was published on one patient with Fanconi anemia who was successfully treated with HSCT [7]. Lastly, also in 1980, a child with osteopetrosis was reported to be treated successfully with HSCT [8]. HSCT has since been used to treat patients with a variety of genetic conditions including inborn errors of metabolism, bone marrow failure syndromes, red blood cell disorders, and platelet disorders [9].

These first major successes exemplify the primary mechanisms of treatment for genetic conditions through HSCT. First, some metabolic conditions are treatable with HSCT by providing donor cells capable of producing an enzyme that is defective or missing from the host. Engrafted donor cells serve as a lifelong source of working enzyme production that is able to circulate and deliver enzymes to other tissues. Importantly, a small fraction of donor monocytes differentiate into microglial cells in the brain and may produce a small amount of enzyme that can be taken up by surrounding neurons. If performed early enough in the disease course, this has the potential to impact central nervous system disease, a key system otherwise unreachable by peripheral enzyme replacement therapy because of its inability to cross the blood-brain barrier [10]. Second, HSCT can be used to replace blood or marrow from various hematopoietic cell lineages. Patients with syndromes associated with pancytopenia (e.g., Fanconi anemia), red blood cell abnormalities (e.g., thalassemia major, Diamond-Blackfan anemia), neutropenia (e.g., severe congenital neutropenia), and thrombocytopenia (e.g., congenital amegakaryocytic thrombocytopenia) can all be treated with HSCT. Lastly, HSCT shows us some cells are HSC derived such as the genetic abnormality in the osteoclasts that results in osteopetrosis. HSCT is used to provide functioning osteoclasts that can properly undergo bony remodeling and hematopoiesis [11].

Although individually the genetic conditions treated with HSCT are rare, collectively they constitute a significant percentage of all HSCTs. Data from the Center for International Blood and Marrow Transplant, which collects and analyzes HSCT data per the C.W. Bill Young Cell Transplantation Program, reveal that 5,800 transplants were performed in 2012 from US donor registries [12•]. An estimated 862 transplants were completed for genetic conditions or associated diseases. The majority of transplants were completed with unrelated donor stem cells $(N=569$, $66.0 \%)$. The others were done using HLA-matched sibling donors $(N=217,25.2 \%)$ or other related donors $(N=76$, $8.8 \%$ ). Autologous HSCTs (stems cells derived from the host) were not used to treat genetic conditions in 2012 as they are expected to be diseased and ineffective at correcting the underlying disease [12॰]. According to HRSA's categories of diseases, the most common indication for transplant associated with genetic conditions was erythrocyte abnormalities $(n=315,36.5 \%)$, followed by disorders of the immune system $(n=255,29.6 \%)$, histiocytic disorders $(n=161,18.7 \%)$, and inborn errors of metabolism $(n=131,15.2 \%)$. Treatment using HSCT has been proven effective, ineffective, and to have mixed or debatable results depending on the genetic condition. Outcomes of HSCT are condition and status specific and are beyond the scope of this article as the focus is on the role of the genetic counselor (see Table 1 for a list of example conditions for which HSCT has been attempted).

\section{The Role of Genetic Counselors in HSCT}

Genetic counselors have traditionally played a role in counseling patients with genetic conditions treated with HSCT; however, their role became more critical with the first patient to undergo HSCT following preimplantation genetic diagnosis (PGD) for Fanconi anemia and HLA typing in 2000 [13]. Genetic counselors helped patients and physicians navigate the genetic, psychosocial, physical, and ethical issues that arose in the aftermath of the discovery of PGD for HLA typing. Both the genetic counselor role and the use of PGD for these purposes have continued to expand over time.

The skills and expertise of genetic counselors are highly transferable to many medical subspecialties including HSCT. The National Society of Genetic Counselors defines genetic counseling as "the process of helping people understand and adapt to the medical, psychological and familial implications of genetic contributions to disease. This process integrates the interpretation of family and medical histories to assess the chance of disease occurrence or recurrence, education about inheritance, testing, management, prevention, resources and research, and counseling to promote informed choices and adaptation to the risk or condition" [14]. Throughout the consideration and process of HSCT, genetic counselors address genetic concerns regarding the natural history and treatment of the disease as well as implications for other family members. Families may benefit from meeting with a genetic counselor during the diagnostic process and prior to as well as after transplantation (Fig. 1).

\section{Diagnosis of a Genetic Condition}

During evaluation for a genetic condition, genetic counselors play a key role by eliciting clinical and family histories, assessing the likelihood of genetic conditions, providing psychosocial assessment and support, and arranging and obtaining consent for appropriate genetic testing. Genetic counselors educate patients and their family members on the potential inheritance patterns and 
Table 1 Categories of genetic conditions treated by HSCT according to HRSA

\begin{tabular}{ll}
\hline Category of disease & $\begin{array}{l}\text { Examples of conditions for which treatment } \\
\text { with HSCT has been attempted }^{\mathrm{a}}\end{array}$
\end{tabular}

Inborn error of metabolism

Inherited abnormalities of erythrocyte differentiation or function

Disorders of the immune system

Histiocytic disorders
Adrenoleukodystrophy, cerebral forms

Beta-glucuronidase deficiency (MPS VII)

Gaucher disease

Globoid cell leukodystrophy

Hunter syndrome (MPS II)

Hurler syndrome (MPS I)

Lesch-Nyhan (HGPRT deficiency)

Mannosidosis

Maroteaux-Lamy syndrome (MPS VI)

Metachromatic leukodystrophy

Mucolipidosis (I cell disease)

Niemann-Pick diseases

Osteopetrosis

Sanfilippo (MPS III)

Wolman disease

Diamond-Blackfan anemia

Fanconi anemia

Other constitutional anemia

Other hemoglobinopathy

Shwachmann-Diamond syndrome

Sickle cell anemia

Sickle thalassemia

Thalassemia major

Bare lymphocyte syndrome

Cartilage hair hypoplasia

CD40 ligand deficiency

Chediak-Higashi syndrome

Chronic granulomatous disease

Common variable immunodeficiency

DiGeorge anomaly

Immune deficiency

Kostmann agranulocytosis

Leukocyte adhesion deficiency

Omenn syndrome

Reticular dysgenesis

Severe combined immunodeficiency (SCID), absence of T and B cells SCID, absence of $\mathrm{T}$, normal B cell

SCID, ADA deficiency severe combined immune deficiency

Wiskott Aldrich syndrome (WAS)

$\mathrm{X}$-linked lymphoproliferative syndrome

Familial erythrohemophagocytic lymphohistiocytosis

Hemophagocytosis

Langerhans cell histiocytosis (histiocytosis-X)

Malignant histiocytosis

a Please note, discussion of the controversies of the success of treatment for each of these conditions is beyond the scope of this article. For some, treatment is known to be effective or non-effective. For others, controversy remains 


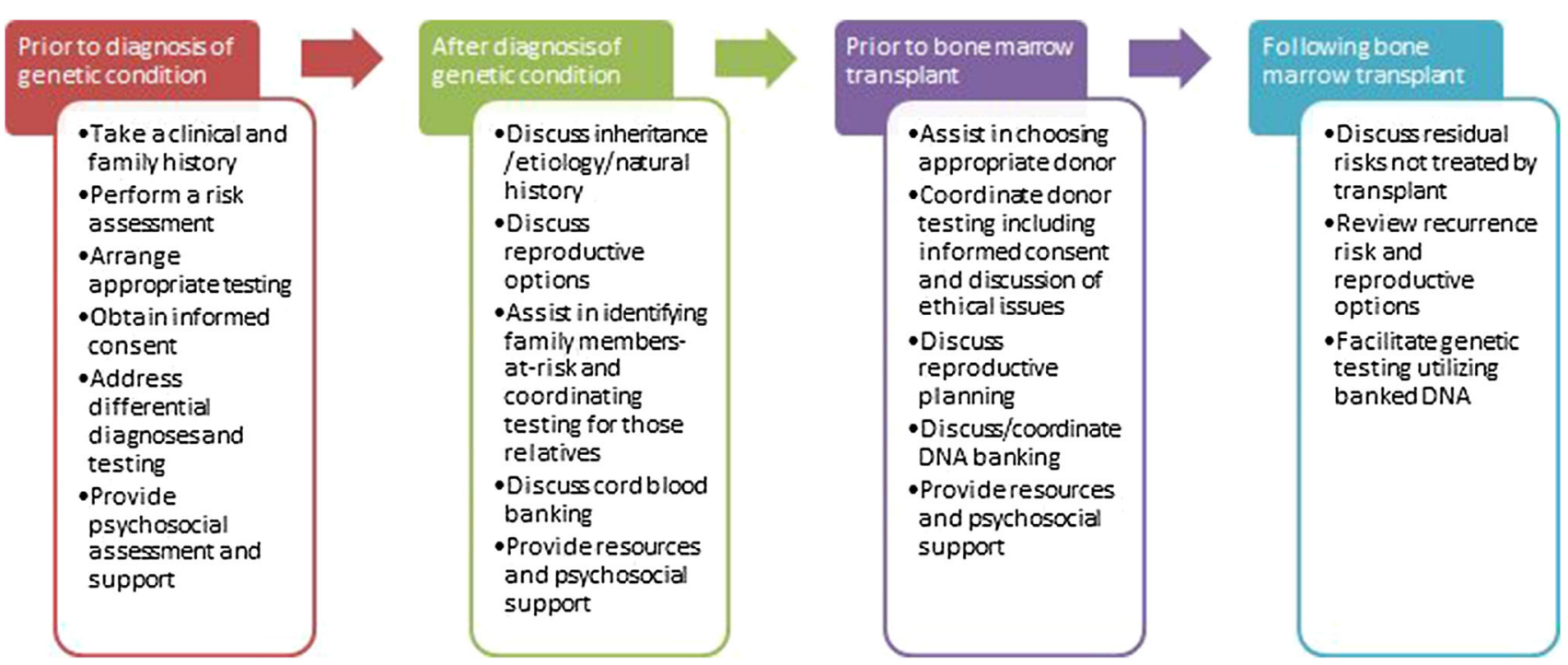

Fig. 1 Potential genetic counseling interactions and timing in the bone marrow transplant process

the natural history of a condition or conditions within the differential diagnosis. They also explain test results and discuss the possible implications for clinical management, treatment, and reproductive decisions. Furthermore, they can address the wide range of associated medical, psychosocial, and ethical issues that may arise before and after results are known [1, 15-17].

In most cases, genetic counseling occurs prior to transplantation with the identification of the genetic condition (e.g., thalassemia, SCID, mucopolysaccharidoses, type 1), yet not all genetic diagnoses are made prior to transplant $[6,18]$. Some genetic conditions may present with leukemia or aplastic anemia and are discovered at the time of transplant, or worse, because of transplant complications. Patients with Fanconi anemia, for example, can have devastating consequences when exposed to normal doses of chemotherapy and radiation; therefore, it is vital to rule out this condition prior to HSCT in patients with aplastic anemia $[19,20]$.

The evaluation of differential diagnoses for genetic conditions prior to transplantation may include making a distinction between the inherited marrow failure syndromes (IBMFS) and acquired aplastic anemia. This is critical to inform choice of therapy and to guide medical management. The recognition of an IBMFS, however, is more difficult than previously acknowledged because of a much wider clinical spectrum compared to classical findings described in early literature for these conditions. For instance, clinical findings may be absent in as many as $25 \%$ of patients with Fanconi anemia [21]. Therefore, only a chromosome breakage cytogenetic analysis using diepoxybutane (DEB) or mitomycin C (MMC) can detect the condition. The North American Pediatric Aplastic Anemia
Consortium (NAPAAC) collaborative working group conducted a survey of its members to determine current practices for the diagnostic workup, treatment, and medical management of pediatric aplastic anemia and identified that $89 \%$ of institutions performed testing for Fanconi anemia, but only $58 \%$ of institutions that perform these tests delayed immunosuppressive therapy or HSCT until results were available [22•]. Similarly, the practices for dyskeratosis congenita, another condition for which there is greater risk for complications and/or sensitivity to treatment [23], are inconsistent in that only $67 \%$ of institutions performed telomere length analysis for the condition [22•]. Some institutions sent molecular genetic testing as an initial test, while others waited for telomere length results in order to determine the need for follow-up genetic testing [22•]. Currently, testing of genes known to be associated with dyskeratosis congenita only detects mutations in $60 \%$ of individuals with the condition [24]. Therefore, although genetic testing may be negative, a patient could still have a telomere shortening disorder that may need to be treated differently than a patient with aplastic anemia who has normal telomere lengths. Additionally, not everyone with Fanconi anemia or dyskeratosis congenita has an abnormal result via chromosome breakage or telomere length analysis $[24,25]$. Due to these complexities, it is important to involve a genetic counselor to interpret family and medical histories to assess the chances of a certain bone marrow failure syndrome and then suggest targeted testing, such as molecular genetic testing for other bone marrow failure syndromes not detectable by chromosome breakage analysis or telomere length analysis.

The rapid proliferation of available laboratory tests has greatly advanced our ability to evaluate genetic causes of 
aplastic anemia, myelodysplastic syndrome (MDS), or even leukemia, but this advancement has also created confusion regarding the indications for and interpretation of such testing. Genetic counselors working with transplant centers are in an excellent position to help provide an appropriate and consistent genetic testing evaluation prior to transplant for medically relevant genetic conditions.

After a diagnosis is made, genetic counselors can help facilitate a discussion of etiology, inheritance, and natural history of the diagnosed condition. Diagnosis of an index case permits diagnostic and/or carrier testing for family members. Patients and their relatives may meet with a genetic counselor to discuss their risks, testing options, and reproductive options including prenatal testing, preimplantation genetic diagnosis (PGD), and assistive reproductive technologies [26]. Medical evaluation and diagnostic testing of family members, particularly siblings, of the affected proband is imperative to their health since, in some conditions, family members sharing the same mutation(s) (e.g., in an IBMFS gene) can manifest highly variable phenotypes and severity of symptoms [27]. For conditions generally diagnosed outside of a genetics clinic, such as X-linked adrenoleukodystrophy, which is commonly diagnosed by neurologists, genetic counselors involved in the HSCT process may be the first to address carrier testing in these families [22, 28, 29]. Parents may also consider carrier testing for reproductive planning (e.g., prenatal testing and PGD), for medical management (e.g., Li-Fraumeni syndrome or types of Fanconi anemia with cancer associated risks), or for determining risk in extended relatives. Carrier testing is also important for genetic testing of newborns or cord blood to determine whether umbilical cord blood should or should not be banked for future use in HSCT. Many transplant centers prefer to store their patients' donor's umbilical cord blood at their treatment facility.

A discussion of the option of PGD should be addressed at the time of diagnosis. The use of PGD in the context of HSCT is primarily two-fold. The first issue is that of recurrence risks. For an inherited condition in which a familial mutation/genetic anomaly is known, PGD is an option for selecting unaffected embryos to implant, thereby greatly reducing the recurrence of that mutation in the pregnancy. The latter is an issue of reducing morbidity and mortality of a living relative who may need a transplant by selecting an embryo that is a good HLA match so that a related donor may be used for HSCT. At the time of the first successful use of PGD for Fanconi anemia and HLA typing, the overall 5-year survival for a Fanconi anemia patient with an unrelated donor was approximately 20-50 \% and an HLA-matched sibling related donor was approximately 70-90\% [30-32]. While both uses of PGD in this context create ethical challenges, the second use highlights the most widely publicized concerns when the technology first arose including the slippery slope to the creation of "designer babies" and the concerns about the autonomy of the child conceived using PGD and HLA typing [33]. In one study of parents of patients with Fanconi anemia, only $30 \%$ of parents were offered information on PGD by a health care professional. This lack of awareness leads to significant consequences in some families such as an irreversible vasectomy [26]. Genetic counselors are experts at navigating the complex genetic, ethical, and medical issues associated with PGD; thus, our recommendation is that all patients who are, or could be, diagnosed with genetic conditions that may be treated with HSCT should be referred for genetic counseling.

Genetic counselors provide patients with resources and psychosocial support. Common psychosocial issues surrounding a diagnosis may include parental guilt of passing on an inherited condition, survivor guilt, anxiety surrounding the genetic testing itself, treatment for the condition, and/or future clinical symptoms [16, 17]. Connecting families with other families with similar diagnoses and experiences can provide important support at the time of diagnosis, and leading up to and during the process of HSCT. Some families find keeping on-line journals or blogs throughout the HSCT process helpful [34]. Additionally, genetic counselors can help interested families identify research opportunities in which the family may be eligible to participate in order to improve efforts to more clearly understand the natural history of a genetic condition.

The time between diagnosis of a genetic condition and need for a HSCT varies significantly by condition. For some conditions, the time taken from diagnosis to transplant is recognized to adversely affect patient HSCT outcomes. As an example, bone marrow transplant in a patient with mucopolysaccharidosis type 1 (Hurler syndrome) should be done as soon as possible as the later the transplant is performed, the less beneficial the transplant becomes [35]. For Hurler syndrome, neuropsychological long-term outcomes and stability are most favorable for children $\leq 2.4$ years whose baseline mental developmental index is greater than 70 , but children transplanted with an index $<70$ show a different trajectory of development with less favorable outcomes [36], whereas in other conditions, such as Fanconi anemia, transplant should be delayed until clinically indicated, usually when bone marrow failure or leukemia occurs [18, 37-39]. In either case, early referral to a transplantation center, selection of HLA-matched donors, and improved supportive care have contributed to the success of HSCT [40]. Patients' psychological outcome post-transplant is impacted by their pre-transplant preparation [41, 42], and patients may find comfort in knowing the benefits, risks, and expectations of HSCT soon after the 
time of genetic diagnosis. Therefore, genetic counselors who are involved in diagnosis can assist families in getting the proper resources and quickly connecting patients to specialized transplant centers, which, in turn, can contribute to better outcomes and patient satisfaction.

\section{Prior to Transplant}

Prior to transplantation, genetic counselors may assist in donor selection, reproductive planning, DNA banking, and addressing psychosocial and medical implications for family members. A common concern prior to transplant is choosing an appropriate donor. Testing of family members for the genetic condition in the proband may be necessary prior to transplant in order to select an optimal donor. Carrier testing of siblings for donor selection purposes is common to avoid choosing an affected donor. If two sibling donors are available, it may be advisable for some conditions to choose a non-carrier donor over a carrier [43]. For example, HSCT may be desired as a treatment for an individual with leukemia due to $\mathrm{Li}$-Fraumeni syndrome. If a TP53 mutation were identified in the proband, it would be vital to determine whether a matched sibling who could potentially serve as a donor also had the TP53 mutation. This involves coordination of testing for the relatives who may serve as a donor, ideally in the context of comprehensive genetic counseling to discuss informed consent, potential ethical issues such as testing of minors for predisposition syndromes, and the communication of test results to family members. While the purpose of testing in this case may be to identify the best donor for the proband, it is imperative that the other implications of possible test results are fully discussed and understood.

Some carriers of autosomal recessive conditions treatable by HSCT may manifest symptoms and thus need referrals and follow-up care coordination. For example, if a child is identified to have Fanconi anemia due to biallelic mutations in BRCA2, the implications of the identification of hereditary breast and ovarian cancer syndrome in family members are far reaching [44]. The psychosocial and medical impact may be even more complicated in the context of a transplant evaluation if incidental results and familial implications are determined when the family's focus is directed toward the individual undergoing HSCT.

Additionally, prior to transplant, genetic counselors could be designated to lead a discussion about reproductive consequences of HSCT and possible reproductive options that can be utilized after HSCT. Options such as semen analysis/banking, oocyte preservation, and embryo preservation are examples of reproductive possibilities that patients may wish to pursue prior to HSCT as a way to preserve fertility post-HSCT. With banked semen or embryos, and possibly oocytes, in vitro fertilization can be pursued in the future. In addition, prior to implantation of embryos, PGD may be performed.

Another important consideration for patients in the pretransplant period is DNA banking to preserve the option of future genetic testing on a DNA specimen known to be from the proband [45]. Banking DNA prior to transplant can reduce or avoid the need of future skin biopsies and/or the complication of testing inappropriate specimens as described in the following section. For example, if a specific diagnosis has not yet been confirmed molecularly, further diagnostic testing post-HSCT may be indicated. Additionally, patients who decline genetic testing pretransplant may change their minds at any point posttransplant and then would need an appropriate specimen to test. As genetic technologies and their uses expand, individuals receiving HSCT from a donor may also desire genetic testing for reasons unrelated to their need for HSCT, and again, an appropriate DNA specimen would need to be available to pursue this option. Lastly, for individuals who do not survive, their family members may desire further diagnostic testing to assess potential recurrence risks that would need to be performed on a banked specimen post mortem.

\section{After Transplant}

Regardless of whether genetic counselors are involved prior to transplant for a genetic condition, genetic counseling issues remain following HSCT. Genetic counselors address a variety of new concerns that typically arise. First, HSCT does not remove the underlying condition, and, in some cases, other manifestations of the condition may still arise. For example, an individual with an IBMFS can be cured of the hematological manifestations of their disease with HSCT; however, following transplant, they still are at an increased risk to develop solid tumors and/or to have a relative with the condition [30]. For an individual with Hurler syndrome, HSCT does not halt the development and progression of skeletal abnormalities, cardiac valve involvement, or certain ophthalmological findings [46]. In addition, once patients have been treated successfully by HSCT, they may be concerned about their reproductive risks. Reproductive options and genetic testing for relatives continue to be issues for discussion following transplant. For fertile patients post-transplant, genetic counseling to discuss options such as prenatal and preimplantation genetic diagnosis, adoption, or egg/sperm donation may be desired to reduce or eliminate the chances of passing an inherited risk. This type of discussion may be ongoing and can be discussed at the time of diagnosis, but also revisited after transplant, when the patient reaches reproductive age or adulthood, before conception, and/or after conception. 
As the inclusion of genetic testing in routine health care continues to expand, it is possible that a patient who has received an HSCT could be offered additional genetic testing later in life. Should genetic testing of the individual who received a transplant from a donor be desired, genetic counselors can assist in having appropriate specimens, such as stored DNA or non-hematologic cells, sent for analysis. Patients and health care providers may need to be reminded that genetic testing for other conditions cannot be performed on peripheral blood cells obtained post-HSCT. This is significant because the peripheral blood cells of the patient after transplant will be representative of the donor's cells and consequently the donor's DNA. Therefore, it is ideal to use pre-transplant banked DNA. If banked DNA is unavailable, cultured skin fibroblast tissue or buccal cells are typically the preferred specimens. Concerns exist with buccal/saliva specimens as the cells may be replaced with cells containing donor DNA because of vascular contamination [47], but some laboratories will perform tests on saliva. Obtaining DNA from cultured skin fibroblast tissue typically requires a skin biopsy; a blood draw done prior to transplant in order to bank DNA would be less invasive.

\section{The Expanding Role of Genetic Counselors in Stem Cell Therapies}

Due to the rapidly changing nature of genetics in medicine, genetic counselors must remain current and grow with cutting edge genetic discoveries. Several recent advancements have impacted individuals with genetic conditions who have been treated with stem cell therapies. One example is the use of HSCT to treat recessive dystrophic epidermolysis bullosa (RDEB), an inherited skin disorder causing severe blistering due to mutations in the type VII collagen gene. In 2010, it was reported that seven patients with RDEB were treated with HSCT with the hypothesis that stem cells derived from the marrow or umbilical cord of donors could be transplanted, travel to the skin, and produce normal collagen type VII [48•]. The authors showed increased collagen type VII production by donor cells in the skin of children with RDEB that persisted months after allogeneic bone marrow transplantation. During this clinical trial, a genetic counselor served to assist families in determining whether the genetic basis of their epidermolysis bullosa met inclusion criteria. In addition, the genetic counselor coordinated genetic counseling and testing of family members for donor selection as well as counseled families regarding PGD. Many genetic counselors serve as coordinators in this type of research study and can play an important role on a translational research team $[49,50]$.

As the next generation of gene therapy trials begins for conditions such as X-linked SCID and X-linked adrenoleukodystrophy, genetic counselors are primed to assist families in the clinical trials process using many of the skills learned through and employed in the HSCT process. In addition, as new forms of stem cells are produced, such as induced pluripotent stem cells, clinical trials will benefit from the incorporation of genetic counselors to assist in the education and counseling of patients. New molecular biology technologies may use whole genome sequencing before and after reprogramming of stem cells, which will likely lead to a variety of incidental findings $[51,52]$. Genetic counselors are trained to help patients navigate complex genetic testing results including the challenge of variants of uncertain significance and incidental findings inherent in this type of testing. Genetic counselors can also help patients and families to navigate the ambiguity of participation in a clinical trial for a new therapy.

\section{Conclusions}

Genetic counseling is an important element of care in many aspects of the lives of patients with genetic conditions, including those treatable by HSCT. In many instances, patients and families must make important life decisions based on genetic information. A multitude of counseling, reproductive, treatment, and psychosocial implications need to be considered. The role of the genetic counselor is essential in determining what information is most important as well as the timing of the information such that patients and families are able to consider psychosocial aspects of the condition and the complexity of the treatment. As new technologies emerge for HSCT, the role of the genetic counselor will also evolve in this process. Genetic counselors are experts at navigating the complex genetic, ethical, and medical issues associated with HSCT. Our recommendation is that all patients who are, or could be, diagnosed with genetic conditions that could be treated with HSCT should be referred for genetic counseling.

Acknowledgments The authors would like to thank Rebecca Tryon, MS, CGC, Janell Kierstein, MS, CGC, and Ralph Quinones, MD, for reviewing this manuscript and for their invaluable contributions and feedback. The authors would also like to thank Curtis Coughlin, MS, CGC, for his contributions to the early development of the manuscript. The authors sincerely appreciate the invitation to submit this manuscript to the Current Genetic Medicine Reports.

Disclosure H. Zierhut declares no conflicts of interest. K. Wolfe Schneider declares no conflicts of interest.

Human and Animal Rights and Informed Consent This article does not contain any studies with human or animal subjects performed by any of the authors. 


\section{References}

Papers of particular interest, published recently, have been highlighted as:

- Of importance

1. Mester JL, Schreiber AH, Moran RT. Genetic counselors: your partners in clinical practice. Clevel Clin J Med. 2012;79:560-8.

2. Bach FH, Amos DB. Hu-1: major histocompatibility locus in man. Science. 1967;156:1506-8.

3. Bortin MM. A compendium of reported human bone marrow transplants. Transplantation. 1970;9:571-87.

4. Gatti RA, Meuwissen HJ, Allen HD, Hong R, Good RA. Immunological reconstitution of sex-linked lymphopenic immunological deficiency. Lancet. 1968;2:1366-9.

5. Thomas ED, Buckner CD, Banaji M, Clift RA, Fefer A, Flournoy $\mathrm{N}$, et al. One hundred patients with acute leukemia treated by chemotherapy, total body irradiation, and allogeneic marrow transplantation. Blood. 1977;49:511-33.

6. Hobbs JR, Hugh-Jones K, Barrett AJ, Byrom N, Chambers D, Henry K, et al. Reversal of clinical features of Hurler's disease and biochemical improvement after treatment by bone-marrow transplantation. Lancet. 1981;2:709-12.

7. Gluckman E, Devergie A, Schaison G, Bussel A, Berger R, Sohier J, et al. Bone marrow transplantation in Fanconi anaemia. $\mathrm{Br}$ J Haematol. 1980;45:557-64.

8. Coccia PF, Krivit W, Cervenka J, Clawson C, Kersey JH, Kim $\mathrm{TH}$, et al. Successful bone-marrow transplantation for infantile malignant osteopetrosis. N Engl J Med. 1980;302:701-8.

9. Steward CG, Jarisch A. Haemopoietic stem cell transplantation for genetic disorders. Arch Dis Child. 2005;90:1259-63.

10. Pastores GM. Therapeutic approaches for lysosomal storage diseases. Ther Adv Endocrinol Metab. 2010;1:177-88.

11. Coccia PF. Hematopoietic cell transplantation for osteopetrosis. In: Blume K, Forman S, Applebaum F, editors. Thomas' hematopoietic cell transplantation, vol. 3. 3rd ed. Malde: Blackwell Publishing Ltd; 2004. p. 1443-54.

12. - C.W. Bill Young Cell Transplantation Program. Health resources and services administration blood cell transplant-US transplant data by center report. 2012. http://bloodcell.transplant. hrsa.gov/research/transplant_data/us_tx_data/data_by_disease/ national.aspx. Accessed 2 Dec 2014. The website contains data on the number and types of HSCTs performed by disease and institution in the US.

13. Grewal SS, Kahn JP, MacMillan ML, Ramsay NKC, Wagner JE. Successful hematopoietic stem cell transplantation for Fanconi anemia from an unaffected HLA-genotype-identical sibling selected using preimplantation genetic diagnosis. Blood. 2004;103:1147-51.

14. Resta R, Biesecker BB, Bennett RL, Blum S, Hahn SE, Strecker $\mathrm{MN}$, et al. A new definition of genetic counseling: National Society of Genetic Counselors' Task Force report. J Genet Couns. 2006;15:77-83.

15. Cohen J, Hoon A, Wilms Floet AM. Providing family guidance in rapidly shifting sand: informed consent for genetic testing. Dev Med Child Neurol. 2013;55:766-8.

16. LeRoy B, Veach PM, Bartels D. Genetic counseling practice. 1st ed. New York: Wiley; 2010. p. 1-415.

17. Weil J. Psychosocial genetic counseling. 1st ed. New York: Oxford University Press; 2000.

18. Nakamura K, Hattori K, Endo F. Newborn screening for lysosomal storage disorders. Am J Med Genet C. 2011;157C:63-71.

19. Gluckman E, Devergie A, Dutreix J. Radiosensitivity in Fanconi anaemia: application to the conditioning regimen for bone marrow transplantation. Br J Haematol. 1983;54:431-40.
20. Berger R, Bernheim A, Gluckman E, Gisselbrecht C. In vitro effect of cyclophosphamide metabolites on chromosomes of Fanconi anaemia patients. Br J Haematol. 1980;45:565-8.

21. Alter BP. Inherited bone marrow failure syndromes. In: Nathan DG, Orkin SH, Look AT, editors. Nathan and Oski's hematology of infancy and childhood. 6th ed. Philadelphia: WB Saunders; 2003. p. 280-365.

22. - Williams DA, Bennett C, Bertuch A, Bessler M, Coates T, Corey $\mathrm{S}$, et al. Diagnosis and treatment of pediatric acquired aplastic anemia (AAA): an initial survey of the North American Pediatric Aplastic Anemia Consortium (NAPAAC). Pediatr Blood Cancer. 2013;61:869-74. Results of the North American Pediatric Aplastic Anemia Consortium that showed heterogeneity in diagnosis and care among pediatric centers. The paper shows the need to develop evidence-based diagnosis and treatment approaches in this rare disease.

23. Dietz AC, Orchard PJ, Baker KS, Giller RH, Savage SA, Alter $\mathrm{BP}$, et al. Disease-specific hematopoietic cell transplantation: nonmyeloablative conditioning regimen for dyskeratosis congenita. Bone Marrow Transplant. 2011;46:98-104.

24. Dokal I. Dyskeratosis congenita. Hematol Am Soc Hematol Educ Program. 2011;2011:480-6.

25. Chirnomas SD, Kupfer GM. The inherited bone marrow failure syndromes. Pediatr Clin North Am. 2013;60:1291-310.

26. Zierhut H, Macmillan ML, Wagner JE, Bartels DM. More than 10 years after the first "savior siblings": parental experiences surrounding preimplantation genetic diagnosis. J Genet Couns. 2013;22:594-602.

27. Shimamura A. Clinical approach to marrow failure. Hematol Am Soc Hematol Educ Program. 2009;1:329-37.

28. Janka GE, Lehmberg K. Hemophagocytic lymphohistiocytosis: pathogenesis and treatment. Hematol Am Soc Hematol Educ Program. 2013;2013:605-11.

29. Tasher D, Dalal I. The genetic basis of severe combined immunodeficiency and its variants. Appl Clin Genet. 2012;5:67-80.

30. MacMillan ML, Wagner JE. Haematopoeitic cell transplantation for Fanconi anaemia — when and how? Br J Haematol. 2010;149: $14-21$.

31. de Latour RP, Porcher R, Dalle J-H, Aljurf M, Korthof ET, Svahn $\mathrm{J}$, et al. Allogeneic hematopoietic stem cell transplantation in Fanconi anemia: the European Group for Blood and Marrow Transplantation experience. Blood. 2013;122:4279-86.

32. MacMillan ML, Blazar BR, Defor TE, Dusenbery KE, Slungaard A, Verneris MR, et al. Alternative donor hematopoietic cell transplantation for patients with Fanconi anemia. Blood. 2012; 120:2918-24.

33. Kahn JP, Mastroianni AC. Creating a stem cell donor: a case study in reproductive genetics. Kennedy Inst Ethics J. 2004;14: 81-96.

34. Ziebland S, Wyke S. Health and illness in a connected world: how might sharing experiences on the internet affect people's health? Milbank Q. 2012;90:219-49.

35. Wynn R. Stem cell transplantation in inherited metabolic disorders. Hematol Am Soc Hematol Educ Program. 2011;2011:285-91.

36. Peters C, Balthazor M, Shapiro EG, King RJ, Kollman C, Hegland JD, et al. Outcome of unrelated donor bone marrow transplantation in 40 children with Hurler syndrome. Blood. 1996;87:4894-902.

37. Van Geel BM, Assies J, Wanders RJA, Barth PG. REVIEW X linked adrenoleukodystrophy: clinical presentation, diagnosis, and therapy. J Neurol Neurosurg Psychiatry. 1997;63:4-14.

38. Bessler M, Parikh S. Recent insights into inherited bone marrow failure syndromes. Curr Opin Pediatr. 2012;24:23-32.

39. Gluckman E, Broxmeyer HA, Auerbach AD, Friedman HS, Douglas GW, Devergie A, et al. Hematopoietic reconstitution in a 
patient with Fanconi's anemia by means of umbilical-cord blood from an HLA-identical sibling. N Engl J Med. 1989;321:1174-8.

40. Eapen M. Allogeneic transplantation for aplastic anemia. Hematology. 2012;17(Suppl 1):S15-7.

41. Stephens M. The lived experience post-autologous haematopoietic stem cell transplant (HSCT): a phenomenological study. Eur J Oncol Nurs. 2005;9:204-15.

42. Perry D. Psychological and social preparation for bone marrow transplantation. Soc Work Health Care. 2000;30:71-92.

43. Au WY, Chan EC, Siu LLP, Lau TCM, Lie AKW, Ma SK, et al. Leukaemic relapse of donor origin after allogeneic bone marrow transplantation from a donor who later developed bronchogenic carcinoma. Br J Haematol. 2002;119:777-80.

44. Lang KA. Genetic counseling for breast cancer risk: how did we get here and where are we going? Expert Rev Mol Diagn. 2013; 13:541-51.

45. Sexton A, Rawlings L, Jenkins M, Winship I. Predictive genetic testing of a bone marrow recipient-ethical issues involving unexpected results, gender issues, test accuracy, and implications for the donor. J Genet Couns. 2014;23:33-7.

46. Muenzer J, Wraith JE, Clarke LA. Mucopolysaccharidosis I: management and treatment guidelines. International Consensus Panel on Management and Treatment of Mucopolysaccharidosis I. Pediatrics. 2009;123:19-29.
47. Jacewicz R, Lewandowski K, Rupa-Matysek J, Jedrzejczyk M, Komarnicki M, Berent J. Genetic investigation of biological materials from patients after stem cell transplantation based on autosomal as well as Y-chromosomal markers. Int J Legal Med. 2013;127:359-62.

48. - Wagner JE, Ishida-Yamamoto A, McGrath JA, Hordinsky M, Keene DR, Woodley DT, et al. Bone marrow transplantation for recessive dystrophic epidermolysis bullosa. $\mathrm{N}$ Engl $\mathrm{J}$ Med. 2010;363:629-39. First reported use of hematopoietic transplantation to treat an inherited skin disorder, recessive dystrophic epidermolysis bullosa, in humans.

49. Zierhut H, Austin J. How inclusion of genetic counselors on the research team can benefit translational science. Sci Transl Med. 2011;3:74cm7.

50. Parrott S, Schneider WK, Baxter S, Campion M, Kumaravel S, Sebold C, et al. 2012 professional status survey: work environment report; 2012. p. 0-50.

51. Green RC, Berg JS, Grody WW, Kalia SS, Korf BR, Martin CL, et al. ACMG recommendations for reporting of incidental findings in clinical exome and genome sequencing. Genet Med. 2013;15:565-74.

52. Lomax GP, Shepard KA. Return of results in translational iPS cell research: considerations for donor informed consent. Stem Cell Res Ther. 2013;4:6. 